\title{
Adolescent Hepatitis C: Prevalence, Impact, and Management Challenges
}

\author{
Paula Chaves Mari \\ Reema Gulati \\ Philip Fragassi
}

Department of Pediatrics, MetroHealth Medical Center, Cleveland, $\mathrm{OH}$, USA
Correspondence: Philip Fragassi MetroHealth Medical Center, 2500 MetroHealth Drive, Cleveland, $\mathrm{OH}$, 44109, USA

Tel + I 2169575000

$\mathrm{Fax}+121625211118$

Email pfragassi@metrohealth.org

\begin{abstract}
The prevalence of Hepatitis C virus infection (HCV), a leading cause of chronic liver disease worldwide, is rising in the United States (US) and other high-income countries, especially among youth and young adults. This surge in cases is closely associated with the opioid crisis and intravenous drug use (IVDU). However, its prevalence and impact on the adolescent population have not been thoroughly studied and therefore is poorly understood. The pediatric population tends to have milder liver disease and progression when compared to adults; however, there is a risk of developing liver cirrhosis, in addition to facing decreased quality of life and stigmatization from the disease. The recent approval of directacting antiviral (DAA) regimens for all $\mathrm{HCV}$ genotypes and age greater than 3 years has revolutionized its management. Therapy has shifted from the prolonged interferon-based regimens, to shorter duration, once daily oral pills that are highly effective, curative and with fewer side effects. Therapy is now indicated for all adolescents with hepatitis $\mathrm{C}$ virus infection, regardless of stage of liver disease, recent IVDU, or coinfection with HIV, therefore eliminating a lifetime risk of chronic liver disease, cirrhosis and hepatocarcinoma. Nonetheless, adolescents are rarely tested or treated for hepatitis $\mathrm{C}$ infection, and very few adolescents complete therapy. Implementation of point of care (POC) testing of high-risk youth at drug treatment centers or other juvenile facilities may be a good strategy to increase testing, diagnosis and therapy. This review article aims to educate pediatricians and other primary care providers to help decrease the existing knowledge gap on the subject.
\end{abstract}

Keywords: HCV, pediatric, IVDU, DAA, opiate

\section{Introduction}

Hepatitis $\mathrm{C}$ virus (HCV) infection is the third most common cause of chronic liver disease in adults in the US, ${ }^{1}$ which results in almost 20,000 deaths per year. ${ }^{2}$ Its estimated direct health care cost was $\$ 6.5$ to $\$ 13.6$ billion from 2000 to $2019 .{ }^{3}$

In divergence to the approval of highly effective, curative direct-acting antiviral (DAA) regimens by the FDA in the last decade, ${ }^{4}$ the prevalence of new HCV infections in the United States (US) has continued to rise significantly. ${ }^{2}$ From 2011 to 2018 , the estimated acute infections per year have tripled, especially among youth and young adults. ${ }^{2}$ This surge in cases is closely associated with the opioid crisis and intravenous drug use (IVDU). ${ }^{5,6}$

In May 2016, the World Health Organization (WHO) posted an advocacy brief with the goal to eliminate hepatitis $\mathrm{C}$ by 2030 . However, the burden of the disease in the pediatric population is still poorly understood. ${ }^{5,7}$ The recent change in the HCV demographics in the US, ${ }^{2,7-9}$ highlights the importance in focusing on the adolescent population in future research in order to reach the WHO's goal. 
Moreover, educating general practitioners and pediatricians is the first step to augment detection and treatment of adolescents with HCV infection.

\section{Prevalence}

The rate of new HCV infections in the US has been increasing since $2009,{ }^{2}$ and its current prevalence is approximately $1 \%$ in adults. ${ }^{10}$ Very few studies have been conducted to investigate its prevalence in the pediatric population,; therefore, it is a lot less understood ${ }^{7}$ and thought to be vastly underestimated. ${ }^{5}$

The estimated worldwide pediatric $\mathrm{HCV}$ prevalence varies from $0.13 \%$ to $0.7 \%{ }^{11,12}$ Most of the pediatric research focuses on high-risk populations: homeless, ${ }^{13}$ infected with Human Immunodeficiency Virus (HIV), ${ }^{11}$ children that live in endemic regions, ${ }^{11}$ and drug rehabilitation centers. ${ }^{14}$ A recent modelling study that reviewed worldwide articles published from 2000 to 2019 estimated the prevalence of $\mathrm{HCV}$ in children in 249 countries; $0.06 \%$ was the estimated current prevalence in the US. ${ }^{11}$ This value is a lot lower than what was detected in an American prevalence study conducted with participants from the Third National Health and Nutrition Examination Survey, from 1988 to 1994, in which seropositivity was $0.2 \%$ in children 6 to 11 years of age, and $0.4 \%$ from 12 to $19 .{ }^{15}$

The prevalence among children is higher in adolescents, likely given the cumulative exposure to risk factors over time, ${ }^{11,16}$ and the older the adolescent, the higher the HCV prevalence. ${ }^{13}$ In Florida, where reporting of all $\mathrm{HCV}$ cases is mandatory, about $49 \%$ of the reported pediatric cases from 2000 to 2009 were among teenagers aged 13 to $18 .^{16}$

The prevalence of HCV and IVDU in adults of a certain population is associated with the prevalence of $\mathrm{HCV}$ in adolescents. ${ }^{11}$ Among people who inject drugs (PWID) the seroprevalence is very high, varying from 10 to $70 \%$ in the US and Europe. ${ }^{17}$

Seven genotypes of $\mathrm{HCV}$ have been described. ${ }^{18}$ Worldwide, the two most common are 1 and $3 .^{18,19}$ In the USA, infection with Genotype 1 is estimated to represent $72.5 \%$ of all HCV infections, followed by genotype 2 $(10.7 \%)$ and $3(8.9 \%) .{ }^{19}$

\section{Routes of Transmission}

In the US, the most common routes of transmission of $\mathrm{HCV}$ are IVDU and multiple sex partners. ${ }^{2,20}$ Globally, the most common cause of $\mathrm{HCV}$ infection in children is through vertical transmission from mother to newborn; ${ }^{5}$ which occurs in about $5.8 \%$ of HCV RNA-positive mothers who are HIV negative, and $10.8 \%$ if there is coinfection with $\mathrm{HIV}^{21}$ However, in the last decade, there has been an increase in incidence of $\mathrm{HCV}$ among adolescents and young adults related to the opioid crisis and IVDU in high-income countries. ${ }^{5}$ The increase in HCV in women of childbearing age resulted in an increased proportion of infants born to HCV-infected mothers in the USA from 2011 to $2014 .^{22}$

The increase in incidence and prevalence of $\mathrm{HCV}$ in the younger population is a recent shift of its demographics in the US. ${ }^{2,7-9}$ A prevalence study from the Center for Disease Control and Prevention (CDC), conducted with state surveillance reports from Kentucky, Tennessee, Virginia and West Virginia, showed that there was a substantial increase in the number of acute $\mathrm{HCV}$ infections in people aged 12 to 29 years of age from 2006 to 2012; within the cases, at least $78 \%$ had intravenous drug use as a risk factor. ${ }^{6}$ A small single centered, observational study that screened adolescents in a drug rehabilitation center demonstrated similar results: all the detected $\mathrm{HCV}$ cases had a history of IVDU. ${ }^{14}$ Non-Hispanic whites, residing in non-urban areas of the USA, comprise most of the young population in which the rise in HCV has been reported. ${ }^{6,9}$

Other less common modes of HCV transmission, but relevant among high-risk adolescents, are unregulated tattoo practices and multiple sexual partners, particularly men who have sex with men (MSM)., ${ }^{2,5}$

\section{Impact}

Hepatitis $\mathrm{C}$ is a leading cause of chronic liver disease with no preventable vaccine. ${ }^{23}$ The infection progresses slowly, over several decades ${ }^{24,25}$ and, in the pediatric population, disease progression is even more insidious when compared to adults. ${ }^{26}$ Nevertheless, the true disease burden in the pediatric population remains poorly understood and hard to measure, given that few studies on long-term follow-up of children with HCV have been published. ${ }^{7,16}$

Even though most pediatric cases are mild or asymptomatic, having chronic HCV can decrease the quality of life of teens and children. ${ }^{27}$ These findings were not reproduced in a later study, which showed no impairment in quality of life, cognitive, behavioral, or emotional functioning in children with $\mathrm{HCV}^{28}$ Yet, $\mathrm{HCV}$ is still considered a stigmatizing condition ${ }^{17}$ and patients often feel discriminated against, both in the health-caresetting and in their workplace. ${ }^{29}$ 


\section{Natural History of Hepatitis C Infection}

Most $\mathrm{HCV}$ infections in the pediatric population are asymptomatic. ${ }^{5,24}$ However, different age groups within the pediatric population are affected in distinct ways.

Acute liver failure (ALF) secondary to HCV in children of any age is extremely uncommon; a cohort study only identified one HCV infection among 348 children that developed $\mathrm{ALF}^{30}$ Infection acquired during infancy is more likely to resolve spontaneously when compared to contracting it at an adult age. ${ }^{31}$ The rate of spontaneous resolution of the infection during childhood without treatment varies from $9 \%,{ }^{32} 11 \%,{ }^{24}$ to $20 \% .{ }^{33}$ However, once the infection has established, it tends to persist into adulthood, which if left untreated, will progress to liver fibrosis, ${ }^{24}$ or liver failure and cirrhosis. ${ }^{24,26,34}$

Bortolotti et al suggested 3 patterns of infections: early clearance of viremia at a young age, asymptomatic viremia persistence with normal or abnormal alanine aminotransferase levels, and early progression to cirrhosis in a minority of patients $(1.6 \%){ }^{24}$ These categories are similar to the ones previously published by the European Paediatric Hepatitis C Virus Network. ${ }^{33}$

Clinical manifestations in children with chronic HCV infection are very rare. Symptoms are normally nonspecific and benign. ${ }^{31}$ Hepatomegaly is the most common manifestation found and, when present, is usually associated with elevated transaminases. ${ }^{33}$ Extrahepatic manifestations, common in adults, are rare in children. ${ }^{5}$

Remarkably, the liver disease in children has a milder course than in adults. Out of 44 children included in a retrospective multicenter study, only 4 had significant fibrosis after a mean of 8 years of infection; and after an average of 5 years, about $70 \%$ of the children had regression or no progression of fibrosis. ${ }^{26} \mathrm{~A}$ multicenter prospective and retrospective study in Japan demonstrated similar results: $91 \%$ of 147 children naive of treatment for $\mathrm{HCV}$ that underwent biopsy had no fibrosis or mild fibrosis at a mean age of 8.9 years. ${ }^{32}$

Even though hepatocellular damage tends to increase with age, ${ }^{5,25,26}$ cirrhosis is extremely uncommon in the pediatric age group. ${ }^{24,26,32}$ No children with cirrhosis were identified in the 30-year epidemiologic study in Japan, ${ }^{32}$ and only one out of 301 in an observational study in Russia. ${ }^{35}$ However, if the infection persists later into adulthood, serious long-term liver disease has been described in as much as $33 \%$ of patients who were infected during childhood. ${ }^{34}$ This retrospective study with 1049
$\mathrm{HCV}$ infected patients during childhood in the United Kingdom estimated that the median time to develop cirrhosis was 33 years; $5 \%$ of the patients were diagnosed with hepatocellular carcinoma, and the median age for its development was found to be 39 years after $\mathrm{HCV}$ infection. $^{34}$

Genotype 1 seems to have a positive correlation with progression of fibrosis ${ }^{26}$ and early progression to cirrhosis. ${ }^{24}$ Other risk factor for persistent viremia and progression to cirrhosis is coinfection with $\mathrm{HIV},{ }^{33,36}$ concomitant alcohol use, ${ }^{34,37}$ male gender, ${ }^{34}$ obesity and diabetes. ${ }^{38}$ Mode of transmission is not a predictive factor for liver fibrosis progression. ${ }^{26,32,34}$

\section{Management Challenges}

Compared to $\mathrm{HCV}$ in adults, there has been little attention paid to management of $\mathrm{HCV}$ in the pediatric population. ${ }^{7,39}$ Even though the identification rate of $\mathrm{HCV}$ in adults is not optimal, it is higher than the diagnosis of the expected HCV cases among children: about $58 \%$ compared to $11.7 \%$, respectively. ${ }^{16}$ One of the possible reasons behind the low rate of diagnosis is the fact that until 2017 there was no approved treatment for children less than 18 years of age,; therefore, few countries have established guidelines for systematic testing and treatment in adolescents. ${ }^{7,40}$

A study performed in Florida demonstrated that only a small fraction of pediatric HCV cases was identified both in the state and in the country, and that only about $1.6 \%$ of the children identified were receiving treatment. ${ }^{16}$

Similarly, a more recent study that looked at electronic medical records of individuals aged 13 to 21 years in the US showed that, among the youth with documented use of any intravenous substance, only $29.6 \%$ were tested for HCV. Furthermore, very few youths diagnosed with HCV end up getting treatment (only one out of 41 with positive viral load); and that most of the youth tested for HCV had no documented IVDU or other specific indication for testing. ${ }^{39}$

Treating adolescents effectively is particularly hard, given that the majority of cases are linked to substance abuse, and therefore there is a high rate of treatment refusal and underutilization of health care. ${ }^{6,8}$ Moreover, multidisciplinary efforts that support adolescents with substance abuse are not widely available, when compared to adults. ${ }^{8}$ Stigmatization in the health-care setting is also a possible barrier for seeking medical help and effective treatment. $^{29}$ 


\section{Diagnosis and Testing}

Typically, screening for HCV starts with testing for antibodies in the blood. If there are no antibodies, there is no need for further testing. ${ }^{41}$ If the antibody is positive, then an RNA test is indicated to confirm current infection. ${ }^{41}$ Suggested diagnostic flow chart in Figure 1.

Antibodies are detected in serum or plasma by thirdgeneration enzyme immunoassays, which is a highly specific (>>99), affordable and practical method. ${ }^{42}$ The HCV antibodies can take 15 weeks after exposure and 5 to 6 weeks after onset of hepatitis to be detectable. ${ }^{43}$ However, HCV RNA can be positive at only 1 to 2 weeks after exposure; many weeks before any elevation of the liver enzymes. ${ }^{43}$

There are approved alternatives to classical serology and virological tests obtained via venipuncture, like point of care testing (POC) and dried blood spots. ${ }^{42,44}$ Rapid diagnostic tests (RDTs) have a sensitivity of $98 \%$ and specificity of $100 \%$, compared to enzyme immunoassays. ${ }^{45}$ In 2010, the Food and Drug Administration (FDA) approved the OraQuick ${ }^{\circledR}$ rapid test for adolescents older than 15 years of age, a POC antibody test, which results in 20 minutes. ${ }^{43}$ This test is also considered an alternative to the initial serology obtained by venipuncture in the CDC guidelines, ${ }^{41}$ the European Association for the Study of the Liver (EASL), ${ }^{46}$ and the WHO. ${ }^{44}$

There are multiple advantages of RDT, like easy implementation in infrastructure limited settings, relatively low cost, being readily available, preventing the necessity to travel to a laboratory after the initial encounter with the ordering provider, and more importantly, providing the opportunity to discuss results and treatment options at the same visit. ${ }^{42,44}$ The latter is of utmost importance to the adolescent population, especially substance users, who have a higher risk of missing follow-up visits. ${ }^{42}$ RDTs are also an ideal option to be used in outreach programs that focus on high-risk populations, such as prisons and drug/ alcohol treatment centers. ${ }^{14,44}$

\section{Genotyping}

Genotyping of the HCV regularly follows the positive viral load. For children and adolescents, it is still used to guide therapy (see therapy section below). In adults, the approval and widespread use of pan-genotypic antiviral therapies resulted in the WHO not to recommend routine genotyping any longer. ${ }^{7}$

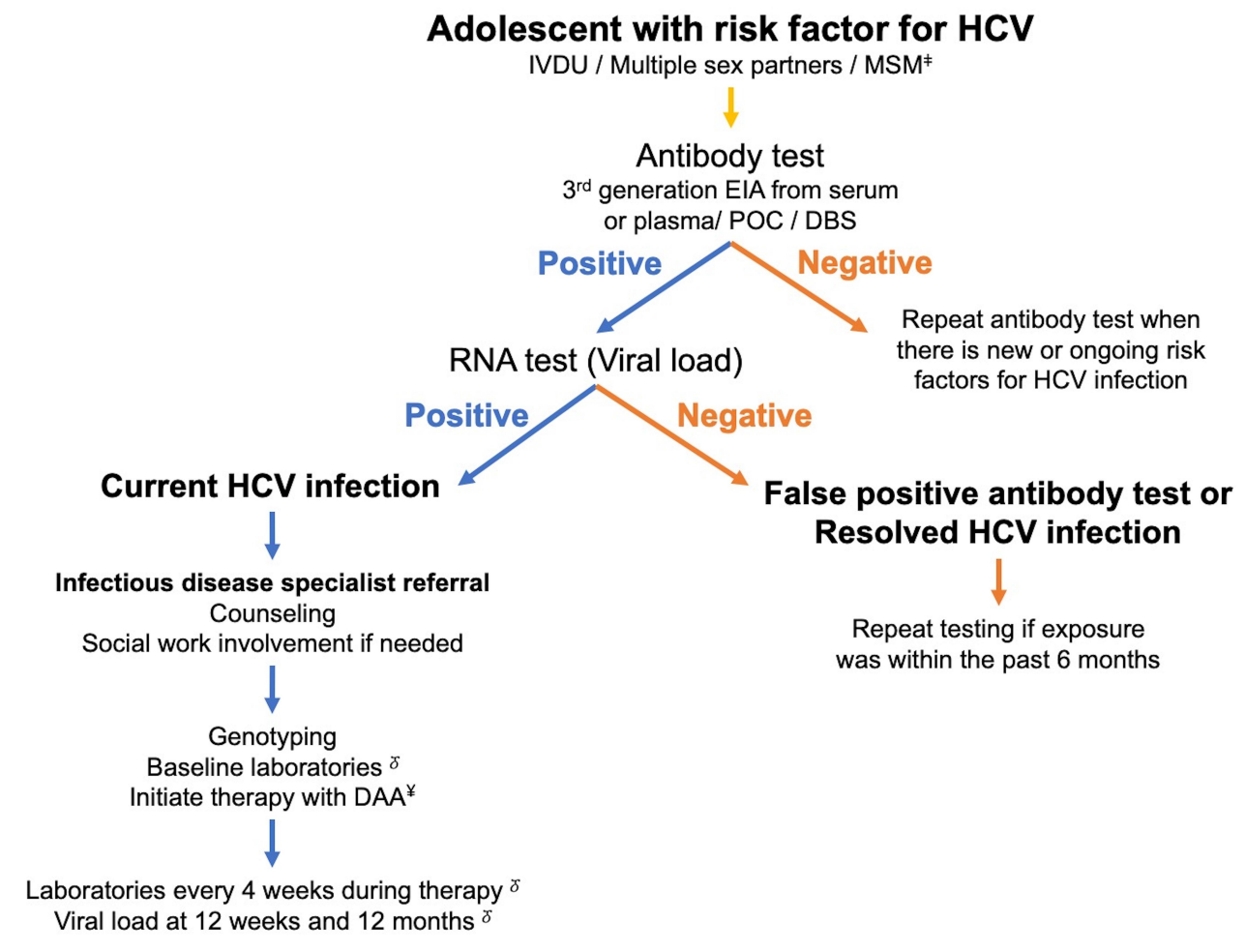

Figure I Flow diagram for HCV diagnosis and management in adolescents.

Notes: ${ }^{\ddagger}$ Specific guidelines for when to test adolescents are not available, but the WHO recommends targeted interventions to these populations ${ }^{60}{ }^{*}$ DAA regimen depends on genotype, patient's age and weight, ${ }^{17,48-50}$ see Table 2. ${ }^{\delta}$ See Table I for details.

Abbreviations: DAA, direct antiviral agent; DBS, dry blood spots; EIA, enzyme immunoassay; HCV, hepatitis Cvirus; IVDU, intravenous drug use; MSM, men who have sex with men; POC, point of care testing. 
Table I Suggested Monitoring for Children and Adolescents with Chronic HCV by the NASPGHAN (Adapted from Leung et al 2020)

\begin{tabular}{|l|l|l|l|}
\hline Test & Pretreatment & During Treatment & Post Treatment \\
\hline AST, ALT, GGT, TB, DB & Annual & Every 4 weeks & $\begin{array}{l}\text { At I2 weeks } \\
\text { If cirrhotic every } 6 \text { months }\end{array}$ \\
\hline CBC & Annual & Every 4 weeks & If clinically indicated \\
\hline PT, INR & Annual & If clinically indicated & If clinically indicated \\
\hline HCV viral load & Annual & Every 4 weeks & At I2 weeks and after 12 months \\
\hline Urine HCG (childbearing aged females) & Prior to treatment & Every 4 weeks if sexually active & N/A \\
\hline AFP & Cirrhotic: every 6 months & N/A & Cirrhotic: every 6 months \\
\hline
\end{tabular}

Abbreviations: AST, aspartate aminotransferase; $A L T$, alanine aminotransferase; GGT, gamma-glutamyl transferase; TB, total bilirubin; DB, direct bilirubin; CBC, complete blood count; PT, prothrombin time; INR, international normalized ratio; HCG, human chorionic gonadotropin; N/A, not applicable; AFP, alpha-fetoprotein.

\section{Long-Term Follow-Up}

Children that have not received therapy for HCV need to be monitored for liver disease progression. ${ }^{17}$ Suggested annual laboratories by the North American Society for Pediatric Gastroenterology, Hepatology and Nutrition (NASPGHAN) are displayed on Table $1 .{ }^{17}$ Serum alpha-fetoprotein (AFP) and abdominal ultrasound are necessary only for patients with cirrhosis. ${ }^{17,31}$ Liver biopsy is not necessary for diagnosis or therapy and indicated only when the result may change management. ${ }^{17,31}$

\section{Therapy}

Although the first oral direct-acting antiviral (DAA) for $\mathrm{HCV}$ in adults was approved almost one decade ago, ${ }^{4}$ the first regimen for children aged 12 to 17 years was approved only in $2017 .{ }^{47}$ Since then, other highly effective regimens for different age groups and genotypes have been approved by the FDA (Table 2). ${ }^{17,48-50}$ The DAAs target different specific proteins products of the $\mathrm{HCV}$, preventing viral replication ${ }^{4,17}$ and most of them result in sustained viremic suppression more than $90 \%$ of the time. ${ }^{7}$ These therapies are extremely more effective, have less adverse

Table 2 Recommended DAA Regimens per Different Guideline for Children Naive of DAA Therapy or Previously Treated with Interferon, without Cirrhosis or with Compensated Cirrhosis

\begin{tabular}{|c|c|c|c|}
\hline Drug Combination/ Guideline & Genotypes & Age/Weight & Duration \\
\hline $\begin{array}{l}\text { Ledipasvir/sofosbuvir } \\
\text { AASLD/IDSA }^{48} \\
\text { ESPGHAN }^{49} \\
\text { NASPGHAN } \\
\text { WHO }^{17}\end{array}$ & $\mathrm{I}, 4,5,6$ & $\geq 3$ years & 12 weeks \\
\hline $\begin{array}{l}\text { Glecaprivir/pibrentasvir } \\
\text { ESPGHAN }^{49} \\
\text { NASPGHAN }^{17}\end{array}$ & Any genotype & $\begin{array}{l}\geq 12 \text { years or } \\
\geq 45 \mathrm{~kg}\end{array}$ & 8 weeks \\
\hline $\begin{array}{l}\text { Sofosbuvir plus Ribavirin } \\
\text { AASLD/IDSA }^{48} \\
\text { ESPGHAN }^{49} \\
\text { NASPGHAN }^{17} \\
\text { WHO }^{50}\end{array}$ & 2,3 & $\geq 3$ years & $\begin{array}{l}12 \text { weeks for genotype } 2 \\
24 \text { weeks for genotype } 3\end{array}$ \\
\hline
\end{tabular}

Note: For specific dosing recommendations refer to each guideline.

Abbreviations: AASLD/IDSA, American Association for the Study of Liver Diseases and Infectious Diseases Society of America; ESPGHAN, European Society for Paediatric Gastroenterology, Hepatology and Nutrition; NASPGHAN, North American Society for Pediatric Gastroenterology, Hepatology and Nutrition; WHO, World Health Organization. 
effects, and last for a shorter duration than the previously interferon-based ones. ${ }^{48}$ DAAs also have lower rates of treatment discontinuation and relapse. ${ }^{49}$

Even though there is approved therapy for children, there is still discussion on when and who to treat. Costeffectivenesshas been demonstrated among adults with mild and moderate liver disease. ${ }^{51}$ In children, early therapy has been proven to be cost-effective at age 12, from a societal standpoint. ${ }^{52}$ The authors of the costeffectiveness study also pointed out the recent increase in $\mathrm{HCV}$ infection among this age group, and the importance of treating children before they develop high-risk behaviors at an older age. ${ }^{52}$

Per the North American and European Society for Pediatric Gastroenterology, Hepatology and Nutrition (NASPGHAN and ESPGHAN) therapy with approved DAA regimen should be considered to any children with chronic HCV infection, in any stage of liver disease, regardless of transaminases levels, aged 3 years and older. ${ }^{17,49}$ Similarly, the WHO recommends treating anyone who is 12 years of age or older and postponing therapy until then if the child is younger. ${ }^{50}$ Locally, however, the recommendation of universal treatment of adolescents with HCV infection is lagging. Only 20 countries out of 122 that have national policies on HCV therapy include adolescents, and 6 of those still recommend interferon-based regimens. ${ }^{40}$

The early eradication of HCV provides either a life without liver disease ${ }^{7}$ or reduction of the cirrhosis decompensation and risk of hepatocellular cancer for patients with more advanced liver disease. ${ }^{43}$ Furthermore, it reduces HCV related stigma to children and adolescents. ${ }^{7,50}$

Currently, in March 2021, there are 3 DAA regimens available for children and adolescents, either treatment naive or previously treated with interferon, without cirrhosis or with compensated cirrhosis (Table 2). There are options for DAA experienced patients and decompensated cirrhosis, ${ }^{46}$ however they will not be covered in this review. Interferon-based therapy is no longer indicated, and therapy should be postponed until there is an approved DAA for age, weight and genotype. ${ }^{49,50}$

Even though early therapy for children has been supported by many health organizations, insurance companies prioritize therapy for patients with advanced liver disease and require prior authorization for most DAA regimens. ${ }^{17}$

\section{Therapy Special Considerations}

\section{Substance Use}

Active, recent drug use or opioid substitution therapy are not contraindications for therapy per the AASLD-IDSA, EASL or WHO guidelines. ${ }^{46,48,50}$ Therapy for people who inject drugs (PWID) should be encouraged given the potential to prevent further spreading of the disease. ${ }^{50}$ The regimens can be used in the same doses under those circumstances. However, because of higher rates of low adherence to therapy, these patients need close follow-upand support systems. ${ }^{46}$ A meta-analysis pooled data from studies conducted with PWID, which showed that there was acceptable adherence to treatment $(82 \%)$, low rate of discontinuation of therapy (22\%) and reinfection (pooled risk of 2.4). ${ }^{53}$ These studies, however, did not include any adolescents.

Moderate alcohol and cannabis use are also not contraindications for therapy. For all patients with multiple drug use, the decision to treat should be individualized. ${ }^{46}$ Therapy centered in substance abuse rehabilitation facilities is highly effective. ${ }^{54}$

\section{HIV/HCV Coinfection}

Liver fibrosis and cirrhosis progresses faster in children and adults with $\mathrm{HIV} / \mathrm{HCV}$ coinfection. ${ }^{36}$ In adults, there are many approved DAA regimens for coinfected patients. All trials have shown similar efficacy when using the same DAA doses and length of therapy indicated for monoinfected individuals. The main challenge in this population is the frequent potential pharmacologic interaction between antiretroviral therapy and DAA, and this must be thoroughly considered when prescribing the regimen. ${ }^{46,55}$ There is no approved DAA regimen in coinfected children or adolescents. ${ }^{17}$

\section{Pregnancy}

There is still no approved DAA therapy for chronic HCV during pregnancy,; however, the need to study its safety and effectiveness during this period has been widely recognized in the literature. ${ }^{56,57}$ During prenatal care, women are screened for HCV and have easier access to health care. Furthermore, treatment during gestation has the potential of preventing vertical transmission. A Phase 1 clinical trial with Ledipasvir plus sofosbuvir has been conducted with promising results: all the 9 women enrolled had sustained viral clearance, all infants had negative viral load upon delivery, and there were no significant severe adverse events among mothers or infants. ${ }^{58}$ There is also an ongoing trial in recruitment phase with 
Sofosbuvir plus Velpatasvir (Clinicaltrials.gov: NCT04382404).

\section{Infection Prevention and Screening}

$\mathrm{HCV}$ infection prevention involves education to increase public awareness on HCV and its transmission. For example, promoting safe injection practices among PWID and protected sex, especially among MSM. ${ }^{7,59}$

Early diagnosis and treatment are also key to prevent new infections in the community. ${ }^{44,59}$ Testing for HCV in the US and other high-income countries is indicated when anyone has risk factors. ${ }^{44}$ Specifically, in the US, HIV, IVDU, recipients of transfusion or organ transplant before 1992, needle sticks or sharp exposures, and children of $\mathrm{HCV}$ positive mothers are a few examples of risk factors that indicate testing for $\mathrm{HCV}^{20}$ The $\mathrm{CDC}$ recently released revised recommendations that expanded testing on adults older than 18 years of age, which included screening for $\mathrm{HCV}$ once in a lifetime, and pregnant women, once every pregnancy, in addition to the previous indications. ${ }^{20}$ These measures will augment detection of both potential perinatal infections, and asymptomatic adults who are spreaders of $\mathrm{HCV}$ in the community.

Guidance on when to test the adolescent population is still lacking globally. ${ }^{40}$ The majority of the countries that have a national $\mathrm{HCV}$ policy have no recommendations for testing or treating children. ${ }^{40}$ The WHO reinforces the importance of testing adolescents that are intravenous drug users, have multiple sex partners or MSM. ${ }^{60}$ Some authors, however, recommend testing all adolescents that admit having any type of high-risk behavior because adolescents are less likely to admit to IVDU to parents or primary care physicians. ${ }^{14,31}$ Others believe that to break the cycle of transmission completely, universal testing of $\mathrm{HCV}$ in the answer. ${ }^{8}$

In the US, the majority of PWID diagnosed with HCV before age 30 report initiation of recreational drugs before age 20 (97\%); prescription opioids and powder cocaine were abused on average 2 years prior to starting heroin use. ${ }^{9}$ Among homeless adolescents, lifetime crack use was a strong predictor of hepatitis infection. ${ }^{13}$ Hence, prevention of early substance abuse during the adolescent years would likely result in lower HCV rates in the same population.

\section{Conclusion}

The increase of HCV infection rates in the last decade related to the opioid crisis has impacted the pediatric population, particularly adolescents and newborns. Future research and effort will have to focus on the pediatric population in order to reach the WHO goal of eradicating HCV by 2030.

The key to prevent long-term morbidity and mortality from HCV infection is early diagnosis and treatment, however there is no clear guideline for when to test adolescents. Pediatricians should be aware of the prevalence of HCV in their acting community and test it in teenagers that report having high-risk behaviors, like IVDU and multiple sexual partners. Even though there is approved, safe and curative treatment for $\mathrm{HCV}$, the adolescent population is not being tested, which delays treatment and increases the morbidity from HCV infection. Establishing widespread RDTs in pediatric offices might increase testing rates, with the advantage of getting the results in the same patient encounter.

On the other hand, the literature has shown that compliance to HCV guidelines is better in drug center facilities than in other settings, like family practices or pharmacies. ${ }^{54}$ Therefore, now that DAA therapy has been approved for patients that are still using drugs or are on medication-assisted therapies, targeting these facilities and providing treatment while these adolescents are admitted might be beneficial. Providing therapy for PWID additionally contributes to diminishing ongoing $\mathrm{HCV}$ transmission. $^{50,51,53}$

Female adolescents that are intravenous drug users, are also prone to other high-risk behaviors, including accidental pregnancy, which perpetuates vertical transmission of the virus. Hopefully, implementing the most recent CDC recommendation in which HCV should be tested in every pregnancy, detection of perinatal infections will increase. Similarly, testing all adults once in a lifetime should have an impact on the pediatric population, given that the prevalence of $\mathrm{HCV}$ in adults predicts the prevalence of $\mathrm{HCV}$ in teenagers of that same population.

Unfortunately, only a small fraction of adolescents diagnosed with $\mathrm{HCV}$ end up getting adequate treatment. When HCV is detected, adequate referral for a pediatric Infectious Diseases provider must occur. It is very likely that families that have members with $\mathrm{HCV}$ have other social issues, which contribute to the lack of compliance to the treatment regimen. Because of the high likelihood of deficient follow up, social services or other support teams should be involved, to assure appropriate follow up and therapy. 


\section{Acknowledgments}

The authors acknowledge the support of Nazha Abughali, MD.

\section{Disclosure}

The authors report no conflicts of interest in this work.

\section{References}

1. Setiawan VW, Stram DO, Porcel J, Lu SC, Le Marchand L, Noureddin M. Prevalence of chronic liver disease and cirrhosis by underlying cause in understudied ethnic groups: the multiethnic cohort. Hepatology. 2016;64(6):1969-1977. doi:10.1002/hep.28677

2. Centers for Disease Control and Prevention. Viral hepatitis surveillance - United States; 2018. https://www.cdc.gov/hepatitis/statistics/ SurveillanceRpts.htm. July 2020. Accessed Dec 13, 2020.

3. Wong JB, McQuillan GM, McHutchison JG, Poynard T. Estimating future hepatitis C morbidity, mortality, and costs in the United States. Am J Public Health. 2000;90(10):1562-1569. doi:10.2105/ ajph.90.10.1562

4. Shah N, Pierce T, Kowdley KV. Review of direct-acting antiviral agents for the treatment of chronic hepatitis C. Expert Opin Investig Drugs. 2013;22(9):1107-1121. doi:10.1517/13543784.2013.806482

5. Squires JE, Balistreri WF. Hepatitis C virus infection in children and adolescents. Hepatol Commun. 2017;1(2):87-98. doi:10.1002/ hep4.1028

6. Zibbell JE, Iqbal K, Patel RC, et al. Increases in hepatitis $\mathrm{C}$ virus infection related to injection drug use among persons aged $\leq 30$ years - Kentucky, Tennessee, Virginia, and West Virginia, 2006-2012. MMWR Morb Mortal Wkly Rep. 2015;64(17):453-458.

7. Indolfi G, Easterbrook P, Dusheiko G, et al. Hepatitis C virus infection in children and adolescents [published correction appears in Lancet Gastroenterol Hepatol. 2020 May;5(5):e4]. Lancet Gastroenterol Hepatol. 2019;4(6):477-487. doi:10.1016/S24681253(19)30046-9

8. Espinosa C, Jhaveri R, Barritt AS. Unique challenges of hepatitis $\mathrm{c}$ in infants, children, and adolescents. Clin Ther. 2018;40(8):1299-1307. doi:10.1016/j.clinthera.2018.07.010

9. Suryaprasad AG, White JZ, Xu F, et al. Emerging epidemic of hepatitis $\mathrm{C}$ virus infections among young nonurban persons who inject drugs in the United States, 2006-2012. Clin Infect Dis. 2014;59(10):1411-1419. doi:10.1093/cid/ciu643

10. Hofmeister MG, Rosenthal EM, Barker LK, et al. Estimating prevalence of hepatitis $\mathrm{C}$ virus infection in the United States, 2013-2016. Hepatology. 2019;69(3):1020-1031. doi:10.1002/ hep.30297

11. Schmelzer J, Dugan E, Blach S, et al. Global prevalence of hepatitis $\mathrm{C}$ virus in children in 2018: a modelling study. Lancet Gastroenterol Hepatol. 2020;5(4):374-392. doi:10.1016/S2468-1253(19)30385-1

12. El-Sayed M, Razavi H. P1263: global estimate of HCV infection in the pediatric and adolescent population. $J$ Hepatol. 2015;62:S831S832. doi:10.1016/s0168-8278(15)31458-6

13. Beech BM, Myers L, Beech DJ. Hepatitis B and C infections among homeless adolescents. Fam Community Health. 2002;25(2):28-36. doi:10.1097/00003727-200207000-00005

14. Fernandes ND, Banik S, Abughali N, Sthapit B, Abdullah N, Fragassi P. Hepatitis $\mathrm{C}$ virus screening among adolescents attending a drug rehabilitation center. J Pediatric Infect Dis Soc. 2020;9 (4):437-441. doi:10.1093/jpids/piz065

15. Alter MJ, Kruszon-Moran D, Nainan OV, et al. The prevalence of hepatitis C virus infection in the United States, 1988 through 1994. $N$ Engl J Med. 1999;341(8):556-562. doi:10.1056/NEJM199908 193410802
16. Delgado-Borrego A, Smith L, Jonas MM, et al. Expected and actual case ascertainment and treatment rates for children infected with hepatitis C in Florida and the United States: epidemiologic evidence from statewide and nationwide surveys. J Pediatr. 2012;161 (5):915-921. doi:10.1016/j.jpeds.2012.05.002

17. Leung DH, Squires JE, Jhaveri R, et al. Hepatitis C in 2020: a north American society for pediatric gastroenterology, hepatology, and nutrition position paper. J Pediatr Gastroenterol Nutr. 2020;71 (3):407-417. doi:10.1097/MPG.0000000000002814

18. Messina JP, Humphreys I, Flaxman A, et al. Global distribution and prevalence of hepatitis C virus genotypes. Hepatology. 2015;61 (1):77-87. doi:10.1002/hep.27259

19. Blach S, Zeuzem S, Manns M; Polaris Observatory HCV Collaborators. Global prevalence and genotype distribution of hepatitis $\mathrm{C}$ virus infection in 2015: a modelling study. Lancet Gastroenterol Hepatol. 2017;2 (3):161-176. doi:10.1016/S2468-1253(16)30181-9

20. Schillie S, Wester C, Osborne M, Wesolowski L, Ryerson AB. CDC recommendations for hepatitis c screening among adults - United States, 2020. MMWR Recomm Rep. 2020;69(2):1-17. doi:10.15585/ mmwr.rr6902a1

21. Benova L, Mohamoud YA, Calvert C, Abu-Raddad LJ. Vertical transmission of hepatitis $\mathrm{C}$ virus: systematic review and meta-analysis. Clin Infect Dis. 2014;59(6):765-773. doi:10.1093/cid/ciu447

22. Schillie SF, Canary L, Koneru A, et al. Hepatitis C virus in women of childbearing age, pregnant women, and children. Am J Prev Med. 2018;55(5):633-641. doi:10.1016/j.amepre.2018.05.029

23. Global Hepatitis Report 2017. Geneva: World Health Organization; 2017.

24. Bortolotti F, Verucchi G, Cammà $\mathrm{C}$, et al. Long-term course of chronic hepatitis $\mathrm{C}$ in children: from viral clearance to end-stage liver disease. Gastroenterology. 2008;134(7):1900-1907. doi:10.1053/j.gastro.2008.02.082

25. Casiraghi MA, De Paschale M, Romanò L, et al. Long-term outcome (35 years) of hepatitis $\mathrm{C}$ after acquisition of infection through mini transfusions of blood given at birth. Hepatology. 2004;39(1):90-96. doi:10.1002/hep.20030

26. Mohan P, Barton BA, Narkewicz MR, et al. Evaluating progression of liver disease from repeat liver biopsies in children with chronic hepatitis C: a retrospective study. Hepatology. 2013;58 (5):1580-1586. doi:10.1002/hep.26519

27. Nydegger A, Srivastava A, Wake M, Smith AL, Hardikar W. Healthrelated quality of life in children with hepatitis $\mathrm{C}$ acquired in the first year of life. J Gastroenterol Hepatol. 2008;23(2):226-230. doi:10.1111/j.1440-1746.2007.04859.x

28. Rodrigue JR, Balistreri W, Haber B, et al. Impact of hepatitis C virus infection on children and their caregivers: quality of life, cognitive, and emotional outcomes. J Pediatr Gastroenterol Nutr. 2009;48 (3):341-347. doi:10.1097/MPG.0b013e318185998f

29. Northrop JM. A dirty little secret: stigma, shame and hepatitis C in the health setting. Med Humanit. 2017;43(4):218-224. doi:10.1136/ medhum-2016-011099

30. Squires RH Jr, Shneider BL, Bucuvalas J, et al. Acute liver failure in children: the first 348 patients in the pediatric acute liver failure study group. $J \quad$ Pediatr. 2006;148(5):652-658. doi:10.1016/j. jpeds.2005.12.051

31. Khaderi S, Shepherd R, Goss JA, Leung DH. Hepatitis C in the pediatric population: transmission, natural history, treatment and liver transplantation. World $J$ Gastroenterol. 2014;20 (32):11281-11286. doi:10.3748/wjg.v20.i32.11281

32. Mizuochi T, Takano T, Yanagi T, et al. Epidemiologic features of 348 children with hepatitis $\mathrm{C}$ virus infection over a 30 -year period: a nationwide survey in Japan. $J$ Gastroenterol. 2018;53(3):419-426. doi:10.1007/s00535-017-1351-0

33. European Paediatric Hepatitis C Virus Network. Three broad modalities in the natural history of vertically acquired hepatitis $\mathrm{C}$ virus infection. Clin Infect Dis. 2005;41(1):45-51. doi:10.1086/430601. 
34. Modin L, Arshad A, Wilkes B, et al. Epidemiology and natural history of hepatitis $\mathrm{C}$ virus infection among children and young people. $J$ Hepatol. 2019;70(3):371-378. doi:10.1016/j.jhep.2018.11.013

35. Turkova A, Volynets GV, Crichton S, et al. Advanced liver disease in Russian children and adolescents with chronic hepatitis C. $J$ Viral Hepat. 2019;26(7):881-892. doi:10.1111/jvh.13093

36. Indolfi G, Bartolini E, Serranti D, Azzari C, Resti M. Hepatitis C in children co-infected with human immunodeficiency virus. J Pediatr Gastroenterol Nutr. 2015;61(4):393-399. doi:10.1097/ MPG.0000000000000895

37. Novo-Veleiro I, Alvela-Suárez L, Chamorro AJ, González-Sarmiento $\mathrm{R}$, Laso FJ, Marcos M. Alcoholic liver disease and hepatitis C virus infection. World J Gastroenterol. 2016;22(4):1411-1420. doi:10.3748/wjg.v22.i4.1411

38. Goossens N, Negro F. The impact of obesity and metabolic syndrome on chronic hepatitis C. Clin Liver Dis. 2014;18(1):147-156. doi:10.1016/j.cld.2013.09.007

39. Epstein RL, Wang J, Hagan L, et al. Hepatitis C virus antibody testing among 13- to 21-Year-olds in a large sample of US federally qualified health centers. JAMA. 2019;322(22):2245-2248. doi:10.1001/jama.2019.16196

40. Malik F, Bailey H, Chan P, et al. Where are the children in national hepatitis $\mathrm{C}$ policies? A global review of national strategic plans and guidelines. JHEP Rep. 2021;3(2):100227. doi:10.1016/j. jhepr.2021.100227

41. Centers for Disease Control and Prevention (CDC). Testing for HCV infection: an update of guidance for clinicians and laboratorians. MMWR Morb Mortal Wkly Rep. 2013;62(18):362-365.

42. Chevaliez S. Strategies for the improvement of HCV testing and diagnosis. Expert Rev Anti Infect Ther. 2019;17(5):341-347. doi:10.1080/14787210.2019.1604221

43. American Academy of Pediatrics. Hepatitis C. In: Kimberlin DW, Brady MT, Jackson MA, Long SS editors, Red Book: 2018 Report of the Committee on Infectious Diseases. 31st. Itasca, IL: American Academy of Pediatrics; 2018:430-431.

44. Easterbrook PJ; WHO Guidelines Development Group. WHO to test and how to test for chronic hepatitis C infection - 2016 WHO testing guidance for low- and middle-income countries. J Hepatol. 2016;65 (1 Suppl):S46-S66. doi:10.1016/j.jhep.2016.08.002

45. Tang W, Chen W, Amini A, et al. Diagnostic accuracy of tests to detect Hepatitis C antibody: a meta-analysis and review of the literature. BMC Infect Dis. 2017;17(Suppl S1):695. doi:10.1186/ s12879-017-2773-2

46. European Association for the Study of the Liver. Electronic address: easloffice@easloffice.eu. EASL recommendations on treatment of hepatitis C 2016. J Hepatol. 2017;66(1):153-194. doi:10.1016/j.jhep.2016.09.

47. Balistreri WF, Murray KF, Rosenthal P, et al. The safety and effectiveness of ledipasvir-sofosbuvir in adolescents 12-17 years old with hepatitis C virus genotype 1 infection. Hepatology. 2017;66 (2):371-378. doi:10.1002/hep.28995
48. Chung RT, Ghany MG, Kim AY; AASLD-IDSA HCV Guidance Panel. Hepatitis C Guidance 2018 Update: AASLD-IDSA recommendations for testing, managing, and treating hepatitis $\mathrm{C}$ virus infection. Clin Infect Dis. 2018;67(10):1477-1492. doi:10.1093/cid/ciy585

49. Indolfi G, Hierro L, Dezsofi A, et al. Treatment of chronic hepatitis c virus infection in children: a position paper by the hepatology committee of European Society of paediatric gastroenterology, hepatology and nutrition. J Pediatr Gastroenterol Nutr. 2018;66 (3):505-515. doi:10.1097/MPG.0000000000001872

50. Guidelines for the care and treatment of persons diagnosed with chronic hepatitis $\mathrm{C}$ virus infection. Geneva: World Health Organization; 2018. Licence: CC BY-NC-SA 3.0 IGO.

51. Martin NK, Vickerman P, Dore GJ, et al. Prioritization of HCV treatment in the direct-acting antiviral era: an economic evaluation. J Hepatol. 2016;65(1):17-25. doi:10.1016/j.jhep.2016.02.007

52. Nguyen J, Barritt AS, Jhaveri R. Cost effectiveness of early treatment with direct-acting antiviral therapy in adolescent patients with hepatitis C virus infection. J Pediatr. 2019;207:90-96. doi:10.1016/j. jpeds.2018.12.012

53. Aspinall EJ, Corson S, Doyle JS, et al. Treatment of hepatitis C virus infection among people who are actively injecting drugs: a systematic review and meta-analysis. Clin Infect Dis. 2013;57(Suppl 2):S80S89. doi:10.1093/cid/cit306

54. Bregenzer A, Conen A, Knuchel J, et al. Management of hepatitis $\mathrm{C}$ in decentralised versus centralised drug substitution programmes and minimally invasive point-of-care tests to close gaps in the HCV cascade. Swiss Med Wkly. 2017;147:w14544. doi:10.4414/ smw.2017.14544

55. Schlabe S, Rockstroh JK. Advances in the treatment of HIV/HCV coinfection in adults. Expert Opin Pharmacother. 2018;19(1):49-64. doi:10.1080/14656566.2017.1419185

56. Freriksen JJM, van Seyen M, Judd A, et al. Review article: direct-acting antivirals for the treatment of HCV during pregnancy and lactation - implications for maternal dosing, foetal exposure, and safety for mother and child. Aliment Pharmacol Ther. 2019;50 (7):738-750. doi:10.1111/apt.15476

57. Nwaohiri A, Schillie S, Bulterys M, Kourtis AP. Towards elimination of hepatitis $\mathrm{C}$ virus infection in children. Lancet Child Adolesc Health. 2018;2(4):235-237. doi:10.1016/S2352-4642(18)30069-5

58. Chappell CA, Scarsi KK, Kirby BJ, et al. Ledipasvir plus sofosbuvir in pregnant women with hepatitis $\mathrm{C}$ virus infection: a phase 1 pharmacokinetic study. Lancet Microbe. 2020;1(5):e200-e208. doi:10.1016/S2666-5247(20)30062-8

59. El-Shabrawi MH, Kamal NM. Burden of pediatric hepatitis C. World J Gastroenterol. 2013;19(44):7880-7888. doi:10.3748/wjg.v19.i44.7880

60. WHO guidelines on hepatitis B and C testing. Geneva: World Health Organization; 2017. Licence: CC BY-NC-SA 3.0 IGO.
Adolescent Health, Medicine and Therapeutics

\section{Publish your work in this journal}

Adolescent Health, Medicine and Therapeutics is an international, peer-reviewed, open access journal focusing on health, pathology, and treatment issues specific to the adolescent age group. All aspects of health maintenance, preventative measures and disease treatmen interventions are addressed within the journal and practitioners from all disciplines are invited to submit their work as well as healthcare researchers and patient support groups. The manuscript management system is completely online and includes a very quick and fair peerreview system. Visit http://www.dovepress.com/testimonials.php to read real quotes from published authors. 